\title{
CONTROLE DE INFECÇÃO EM CIRURGIA GERAL - RESULTADO DE UM ESTUDO PROSPECTIVO DE 23 ANOS E 42.274 CIRURGIAS
}

\section{INFECTION CONTROL IN GENERAL SURGERY: RESULTS OF A PROSPECTIVE STUDY IN 42,274 SURGERIES DURING 23 YEARS}

\author{
Edmundo Machado Ferraz TCBC-PE \\ Álvaro Antônio Bandeira Ferraz TCBC-PE ${ }^{2}$ \\ Tércio Souto Bacelar TCBC-PE ${ }^{2}$ \\ Helena Suely T. D'Albuquerque ${ }^{3}$ \\ Maria das Dores Maia M. Vasconcelos ${ }^{3}$ \\ Cristiano Souza Leão ${ }^{4}$
}

\begin{abstract}
RESUMO: Objetivo: O objetivo deste trabalho foi de avaliar uma metodologia simples adotada há 23 anos em um hospital público universitário no controle das infecções pós-cirúrgicas. Método: A casuística estudada compreende um total de 42.274 cirurgias realizadas no Serviço de Cirurgia Geral do Hospital das Clínicas da Universidade Federal de Pernambuco (UFPE) (janeiro de 1977 a dezembro de 1999). Os dados foram obtidos através um sistema de busca ativa de infecção e de um sistema de vigilância epidemiológica de seguimento pós-operatório, no ambulatório de egressos. A Comissão de Controle de Infecção Hospitalar (CCIH) do Hospital das Clínicas (HC) da UFPE concentrou sua atuação na prevenção, dando ênfase ao: diagnóstico preciso dos casos de infecção; higiene corporal; controle das afecções associadas; internamento pré-operatório; cuidados com tricotomia; antisepsia e assepsia; técnica cirúrgica adequada; divulgação dos resultados e da relação infecção/cirurgião/anestesista e rigoroso controle de antimicrobianos. Resultados: A taxa de infecção de ferida passou de índices em torno de $15-20 \%$ para os atuais $7,7 \%$. A infecção urinária foi reduzida de $18,2 \%$ para $0,4 \%$, e a infecção respiratória de $22,9 \%$ para $2,7 \%$. A mortalidade em decorrência de infecção foi reduzida de $2,8 \%$ para os atuais $0,9 \%$ e a taxa de infecção de ferida em cirurgia limpa de $12,8 \%$ para $3,4 \%$. Na cirurgia ambulatorial, das 27.580 operações a taxa de infecção de ferida foi de $0,4 \%$ e a mortalidade de $0,007 \%$. Conclusão: O que tentamos comprovar com a divulgação de nossos resultados é que controle de infecção se faz com decisão política, força de vontade e motivação em controlar o problema da infecção hospitalar.
\end{abstract}

Descritores: Controle de infecção; Infecção hospitalar; Infecção de ferida; Infecção respiratória; Infecção urinária; Infecção em cirurgia.

\section{INTRODUÇÃO}

A cirurgia e o controle clínico do paciente cirúrgico apresentaram nos últimos anos avanços importantes que refletiram diretamente em uma queda nas taxas de morbi-mortalidade de pacientes submetidos a procedimentos cirúrgicos.
Contudo, a infecção pós-operatória ainda representa uma complicação importante, cobrando um elevado tributo em mortalidade, morbidade e custo direto, indireto e intangível ao tratamento médico do paciente.

A infecção é uma complicação inerente ao ato cirúrgico e se faz necessário um grande esforço para mantê-la

1. Professor Titular de Cirurgia Abdominal e Bases da Técnica Cirúrgica da Universidade Federal de Pernambuco. Chefe do Serviço de Cirurgia Geral do Hospital das Clínicas da Universidade Federal de Pernambuco.

2. Professor Adjunto do Departamento de Cirurgia da Universidade Federal de Pernambuco.

3. Enfermeira da Comissão de Controle de Infecção Hospitalar do Hospital das Clínicas da UFPE.

4. Médico Residente do Serviço de Cirurgia Geral do Hospital das Clínicas da UFPE.

Recebido em 16/6/2000

Aceito para publicação em 11/10/2000

Trabalho realizado no Serviço de Cirurgia Geral do Hospital das Clínicas da UFPE. 
sob controle e em níveis aceitáveis, dentro dos padrões de uma determinada instituição hospitalar, de tal modo que a análise de seus índices constitui, hoje, um parâmetro de controle de qualidade do serviço prestado por um hospital.

O custo do tratamento da infecção da ferida cirúrgica no Hospital das Clínicas da UFPE foi de US\$ 1,400.00 para uma cirurgia de colecistectomia, US $\$ 500.00$ para uma operação cesariana e US \$1,100.00 para uma gastrectomia total, elevando ainda, a permanência hospitalar em 12,4 e 14 dias respectivamente ${ }^{1}$.

O paciente cirúrgico típico dos anos 60 e 70 sofreu uma profunda modificação. Na década de 1990 e no limiar do ano 2000, passaram a predominar na clientela do nosso hospital pacientes idosos, imunodeprimidos, portadores de neoplasias e em uso de quimio e radioterapia, pacientes transplantados em uso de drogas imunossupressoras. Ou seja, pacientes de alto risco de infecção, nos quais são utilizados procedimentos cada vez mais invasivos no diagnóstico e na terapêutica, além da utilização de antimicrobianos de espectro mais amplo, fazendo surgir bactérias mais resistentes e agressivas ${ }^{2,3}$.

A taxa de pacientes submetidos a cirurgias limpas, que na maioria dos hospitais no mundo inteiro supera $70 \%$, é inferior a $50 \%$ em nosso serviço. A taxa de pacientes submetidos a cirurgias contaminadas ou infectadas gira em torno de 5-10\%, enquanto que no HC da UFPE é de cerca de $40 \%{ }^{4}$.

Se este fato ocorreu com o paciente cirúrgico, importantes e significativas mudanças aconteceram com os agentes etiológicos. As bactérias Gram-negativas (E. coli, Klebisiella), responsáveis até então pelas infecções póscirúrgicas, estão dando lugar à bactérias Gram-positivas, Pseudomonas e Cândida, assim como, a um aumento considerável dos níveis de resistência dessas bactérias a antibióticos rotineiramente usados na clínica cirúrgica ${ }^{5}$.

$\mathrm{O}$ aumento da resistência bacteriana nos Estados Unidos tem provocado um custo anual estimado em 100300 milhões de dólares. O nível de resistência está diretamente relacionado à quantidade e ao modo de utilização do antibiótico naquele ambiente $e^{4-6}$.

Além dessas mudanças de perfil no paciente cirúrgico e com o agente agressor, o hospital também sofreu importante modificação. Hospitais de alta complexidade passaram a se comportar como centros de referência, recebendo predominantemente este tipo de paciente e albergando exatamente microrganismos selecionados por sua competência ${ }^{4}$.

No Brasil, as sucessivas crises econômicas deterioraram a maioria dos hospitais públicos, que, em última análise, em virtude de um sistema de saúde perverso que atende a pacientes sem recursos e desnutridos e os oriundos da assistência privada e/ou seguro saúde que referem os pacientes mais graves e onerosos, tornaram-se inviáveis economicamente.

Este fato também levou a um incremento da cirurgia ambulatorial, que permite três grandes vantagens: menor custo, menor taxa de infecção e um maior número de atendimentos. Isto conseqüentemente, faz com que abra a possibilidade de se atender mais pacientes graves, complexos, onerosos, de maior risco de infecção e de maior média de permanência hospitalar ${ }^{3}$.
Por todos esses motivos a infecção cirúrgica apresenta interface com outras doenças do ambiente hospitalar, justificando a grande preocupação das instituições com o seu aparecimento e controle, fazendo surgir deste modo, as comissões de controle de infecção e toda uma tecnologia de interferência e controle desta complicação.

Várias medidas têm sido propostas para reduzir e controlar o problema da infecção cirúrgica, mas é evidente que o principal fator que poderá interferir com este problema é a educação da comunidade hospitalar.

O objetivo deste trabalho foi de avaliar uma metodologia simples, barata e exeqüível a qualquer hospital do mundo, adotada há 23 anos em um hospital público, do Nordeste brasileiro no controle das infecções pós-cirúrgicas.

\section{MÉTODOS}

A casuística estudada compreende um total de 42.274 cirurgias realizadas no Serviço de Cirurgia Geral do Hospital das Clínicas da Universidade Federal de Pernambuco (HC da UFPE), no período de primeiro de janeiro de 1977 a 31 de dezembro de 1999. Dentre essas operações 27.580 foram realizadas em regime ambulatorial.

Os dados foram analisados de acordo com as informações contidas nas fichas de controle de infecção, que são anexadas ao prontuário de cada paciente, sendo, após a alta, encaminhadas à Comissão de Controle de Infecção Hospitalar (CCIH) do HC da UFPE. Os dados foram obtidos por um sistema de busca ativa de infecção realizado pela enfermagem da CCIH e de um sistema de vigilância epidemiológica de seguimento pós-operatório, no ambulatório de egressos, que acompanha o paciente cirúrgico após a alta hospitalar ${ }^{7}$.

As cirurgias foram classificadas segundo o risco de contaminação $0^{2,3} \mathrm{em}$ limpa, potencialmente contaminada, contaminada e infectada, de acordo com recomendações dos Colégios Americano ${ }^{8}$ e Brasileiro de Cirurgiões ${ }^{9,10}$, e assim definidas:

- Limpas: são as de reduzido potencial de infecção. Não ocorre abertura de vísceras ocas ou infração da técnica asséptica.

- Potencialmente contaminadas: ocorre abertura de víscera oca, com mínimo de extravasamento de conteúdo ou pequenas infrações técnicas.

- Contaminadas: abertura de víscera oca com grosseiro extravasamento de conteúdo, inflamação aguda sem pus, infrações grosseiras na técnica asséptica e lesões traumáticas com menos de seis horas.

- Infectadas: presença de pus, víscera oca perfurada e lesões traumáticas com mais de seis horas de evolução.

Quando da admissão, os pacientes eram examinados e orientados no que se refere ao banho com lavagem da cabeça e do local da cirurgia, tricotomia 1-2 horas antes da intervenção e quando indicado, preparo mecânico dos cólons. A identificação de infecção comunitária associada à afecção cirúrgica determinou a suspensão do procedimento eletivo e o paciente teve o tratamento desta infecção instituído. 
Os pacientes durante o período pós-operatório, quando internados, foram visitados pela enfermagem da $\mathrm{CCIH}$, que em um sistema de busca ativa, verificava o estado da ferida operatória, o uso de antimicrobianos, curva térmica, queixas urinárias e respiratórias, além de infecções associadas. Por ocasião da alta o paciente era orientado a retornar ao Ambulatório de Egressos da $\mathrm{CCIH}$, que centraliza o retorno de todos os pacientes cirúrgicos do hospital. Nesta ocasião, supervisionava-se o estado da ferida, com realização de curativos, retirada dos pontos cirúrgicos, investigava-se queixas urinárias e respiratórias, e então eram orientados a retornarem aos ambulatórios especializados. Este retorno ao ambulatório se dá em torno do décimo ao 15 ia de pós-operatório.

A presença de pus foi o critério utilizado para classificar a ferida como infectada. O diagnóstico da infecção respiratória foi eminentemente clínico (tosse produtiva, alterações radiológicas e febre). O diagnóstico da infecção urinária se baseou no resultado da urocultura. Uroculturas com mais de 100.000 colônias/ml foram considerados positivas. Paciente com um número de colônias menor, mas com sintomatologia urinária também foi considerado como positivo. A CCIH divulgou uma política de indicação restrita de cateterismo urinário, com padronização de técnica asséptica e utilização de sistema de drenagem fechado.

A utilização de antimicrobianos no HC da UFPE apresenta um controle bastante rígido. Após várias reuniões da $\mathrm{CCIH}$ e todos os Serviços do Hospital existe uma lista de 15 antibióticos de livre prescrição pelo corpo clínico do hospital $^{3}$. São os antibióticos de primeira linha, e que são prescritos em um impresso específico de controle. Esta lista tem sido modificada com o tempo e com a necessidade dos serviços. Caso o médico considere necessária a utilização de um antibiótico não constante na lista de livre prescrição, terá de apresentar uma justificativa da sua requisição e esta é analisada pelo médico da CCIH que decidirá ou não pela liberação da medicação. Em caso de dúvidas, o médico é chamado a discutir com a CCIH a indicação e outras alternativas.

A utilização do antibiótico de maneira profilática, se deu preferencialmente em dose única, com cefazolina, na indução anestésica. Caso o procedimento cirúrgico se prolongasse por mais de três horas o antibiótico era reutilizado, mas suspenso ao término da cirurgia ${ }^{3,6,11,12}$. Outros esquemas poderiam ser utilizados de acordo com a cartilha e a concordância da CCIH (Ex.: cirurgia cólon).

A CCIH realiza relatórios mensais internos e relatórios trimestrais aos serviços do hospital. São divulgadas nestes relatórios taxas específicas relacionando infecção de ferida em cirurgia limpa e o cirurgião, e taxas de infecção respiratória pós-operatória e o anestesista.

Os pacientes submetidos a procedimentos ambulatoriais deram entrada no hospital, no setor de cirurgia ambulatorial, onde foram examinados e tiveram seus procedi- mentos realizados. Após a cirurgia os pacientes se recuperavam em uma sala e antes da alta eram reexaminados pelo médico residente e liberados com orientação de retornar ao ambulatório de egressos para serem acompanhado e ter os pontos retirados. Toda a orientação de tricotomia e banho pré-operatório era realizada no ambulatório, no momento da marcação cirúrgica.

\section{RESULTADOS}

A incidência de infecções de ferida, urinária , respiratória e a mortalidade relacionada à infecção pós-operatória, no período de primeiro de janeiro de 1977 a 31 de dezembro de 1999, está expressa na Tabela 1. A representação gráfica da incidência de infecção de ferida está representada no Gráfico 1, enquanto que as infecções urinária e respiratória, nos Gráficos 2 e 3, respectivamente. A representação gráfica da mortalidade se encontra no Gráfico 5.

A incidência de infecção de ferida em cirurgias limpas esta representado na Tabela 2 . As cirurgias limpas compreenderam $41,9 \%$ do total de cirurgias realizadas pelo Serviço de Cirurgia Geral do HC da UFPE. A representação gráfica encontra-se no Gráfico 4.

A taxa de infecção de ferida e mortalidade nas cirurgias realizadas em regime ambulatorial estão expressas na Tabela 3. A mortalidade de dois casos se deu em uma exérese de cisto sebáceo de uma paciente diabética que evoluiu com uma fasciíte necrotizante e sepse. $\mathrm{O}$ outro caso de óbito se deu em uma ressecção de tumor maligno cutâneo com invasão óssea que também evoluiu com sepse e óbito.

$\mathrm{O}$ resultados das culturas das infecções de ferida mostraram um predomínio de Staphylococcus aureus, com exceção dos anos de 1979 e 1985, em que houve um predomínio de Enterobacter sp.

\section{DISCUSSÃO}

O Hospital das Clínicas da UFPE é um hospital terciário que realiza cirurgia de alta complexidade (transplantes de fígado e rim, cirurgia de obesidade mórbida etc.) e abrange toda a área de Pernambuco e é referência para o NorteNordeste. Deste modo, o Serviço de Cirurgia Geral do HCUFPE tem em sua clientela uma população mais suscetível à infecção, pois são pacientes com doenças graves que comprometem o estado geral e nutricional, além de fazerem parte de uma região em que o déficit nutricional é importante. Estudo realizado no próprio HC da UFPE, avaliando o aspecto nutricional e imunológico de 350 pacientes consecutivos, verificou que apenas $10,57 \%$ destes foram considerados como dentro da normalidade ${ }^{13}$. Outro dado importante é que, apenas $41,9 \%$ dos nossos pacientes submeteram-se a procedimentos limpos, corroborando ainda mais, o tipo de clientela de alto risco que procura a nossa instituição, pois esta taxa na casuística mundial é em torno de $70 \%{ }^{4}$. 
Tabela 1

Incidência de infecção em cirurgia no período de 23 anos

\begin{tabular}{|c|c|c|c|c|c|c|c|c|c|}
\hline Ano & № Cirurgias & & rida & Infecç & nária & $\operatorname{Inf}$ & esp. & $M o l$ & $c ̧ \tilde{a} o$ \\
\hline & & № & $\%$ & $N^{\underline{o}}$ & $\%$ & Noo & $\%$ & NNo & $\%$ \\
\hline 1977 & 357 & 58 & 16,2 & 65 & 18,2 & 82 & 22,9 & 10 & 2,8 \\
\hline 1978 & 403 & 61 & 15,1 & 18 & 4,5 & 29 & 7,2 & 06 & 1,5 \\
\hline 1979 & 483 & 97 & 20,1 & 31 & 5,2 & 77 & 15,9 & 03 & 0,6 \\
\hline 1980 & 404 & 75 & 18,5 & 12 & 3,0 & 28 & 6,9 & 06 & 1,5 \\
\hline 1981 & 427 & 81 & 18,9 & 19 & 4,4 & 18 & 4,2 & 04 & 0,9 \\
\hline 1982 & 324 & 39 & 12,0 & 12 & 3,7 & 16 & 4,9 & 02 & 1,1 \\
\hline 1983 & 781 & 60 & 7,7 & 16 & 2,0 & 10 & 1,3 & 05 & 0,6 \\
\hline 1984 & 590 & 50 & 7,5 & 12 & 2,0 & 04 & 0,7 & 07 & 1,2 \\
\hline 1985 & 966 & 68 & 7,0 & 17 & 1,7 & 25 & 2,6 & 06 & 0,6 \\
\hline 1986 & 803 & 35 & 4,3 & 24 & 3,0 & 15 & 1,8 & 05 & 0,6 \\
\hline 1987 & 513 & 56 & 10,9 & 15 & 2,9 & 11 & 2,1 & 05 & 1,0 \\
\hline 1988 & 656 & 67 & 10,2 & 17 & 2,6 & 20 & 3,0 & 05 & 0,8 \\
\hline 1989 & 620 & 61 & 9,8 & 15 & 2,4 & 08 & 1,3 & 07 & 1,1 \\
\hline 1990 & 403 & 37 & 9,2 & 05 & 1,2 & 06 & 1,5 & 06 & 1,5 \\
\hline 1991 & 656 & 66 & 10,0 & 19 & 2,9 & 17 & 2,6 & 11 & 1,7 \\
\hline 1992 & 731 & 82 & 11,2 & 18 & 2,5 & 50 & 6,8 & 09 & 1,2 \\
\hline 1993 & 706 & 75 & 10,6 & 16 & 2,3 & 29 & 4,1 & 09 & 1,3 \\
\hline 1994 & 702 & 89 & 12,7 & 14 & 1,9 & 33 & 4,7 & 08 & 1,1 \\
\hline 1995 & 753 & 78 & 10,4 & 26 & 3,5 & 32 & 4,2 & 14 & 1,8 \\
\hline 1996 & 860 & 99 & 11,5 & 13 & 1,5 & 18 & 2,0 & 13 & 1,5 \\
\hline 1997 & 876 & 138 & 7,2 & 21 & 1,1 & 26 & 1,4 & 10 & 1,1 \\
\hline 1998 & 787 & 81 & 10,3 & 0,8 & 1,0 & 10 & 1,3 & 06 & 0,7 \\
\hline 1999 & 893 & 69 & 7,7 & 0,4 & 0,4 & 24 & 2,7 & 08 & 0,9 \\
\hline TOTA & 14.694 & 1.622 & 11,0 & 417 & 2,8 & 588 & 4,0 & 147 & 1,1 \\
\hline
\end{tabular}

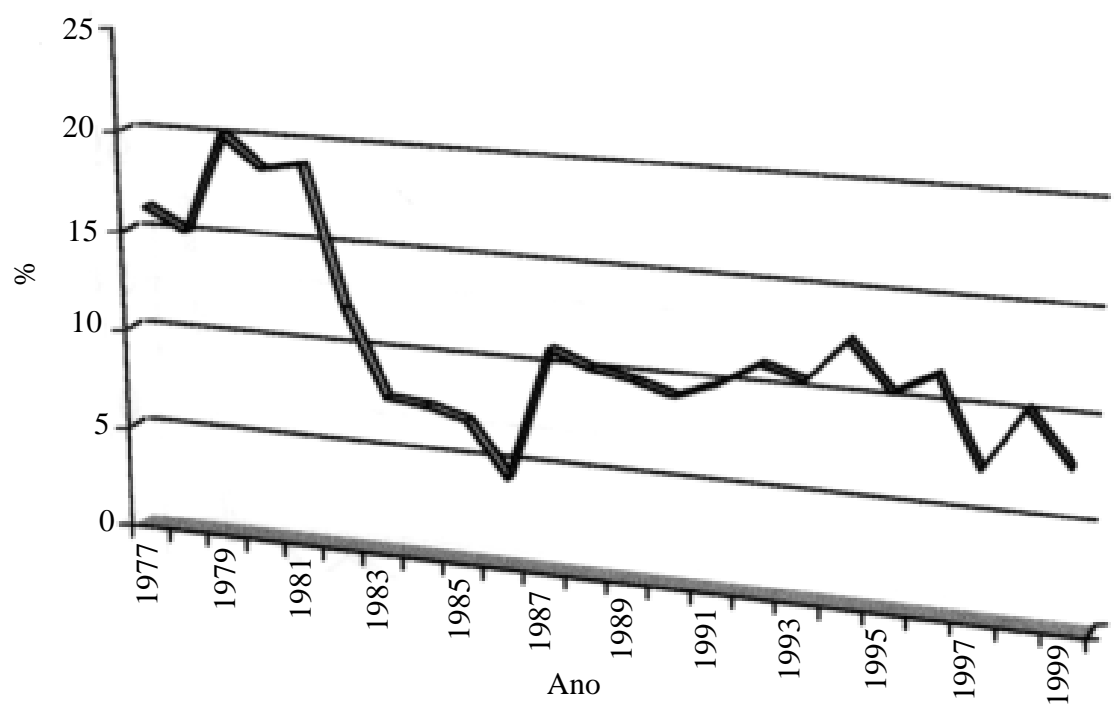

Gráfico 1 - Distribuição da curva de Infecção de Ferida no período de 1977-1999.

No entanto, é sabido que cerca de $30 \%$ das infecções hospitalares, são evitáveis ${ }^{2,14}$. No HC-UFPE, utilizamos uma metodologia própria, que se baseia em um sistema de vigilância epidemiológica rigoroso e um processo continuado de educação da comunidade do hospital. Esta metodologia tem determinado resultados amplamente satisfató- rios, dentro da realidade de um hospital público brasileiro, do tipo de clientela atendida e, principalmente, semelhantes às taxas divulgadas na literatura internacional ${ }^{2,3}$.

Nem sempre taxa elevada de infecção significa descuido com o problema. Muitas vezes, traduz metodologia apurada, diagnóstico preciso e clientela de alto risco. 


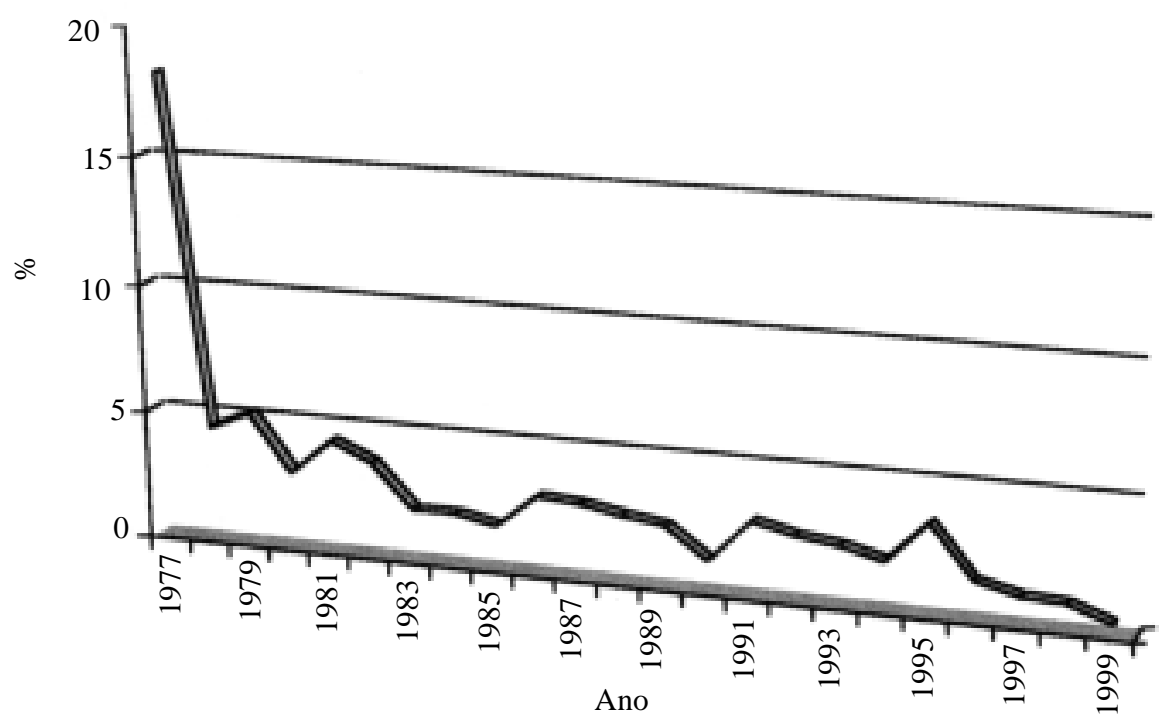

Gráfico 2 - Distribuição da curva de Infecção Urinária no período de 1977-1999.

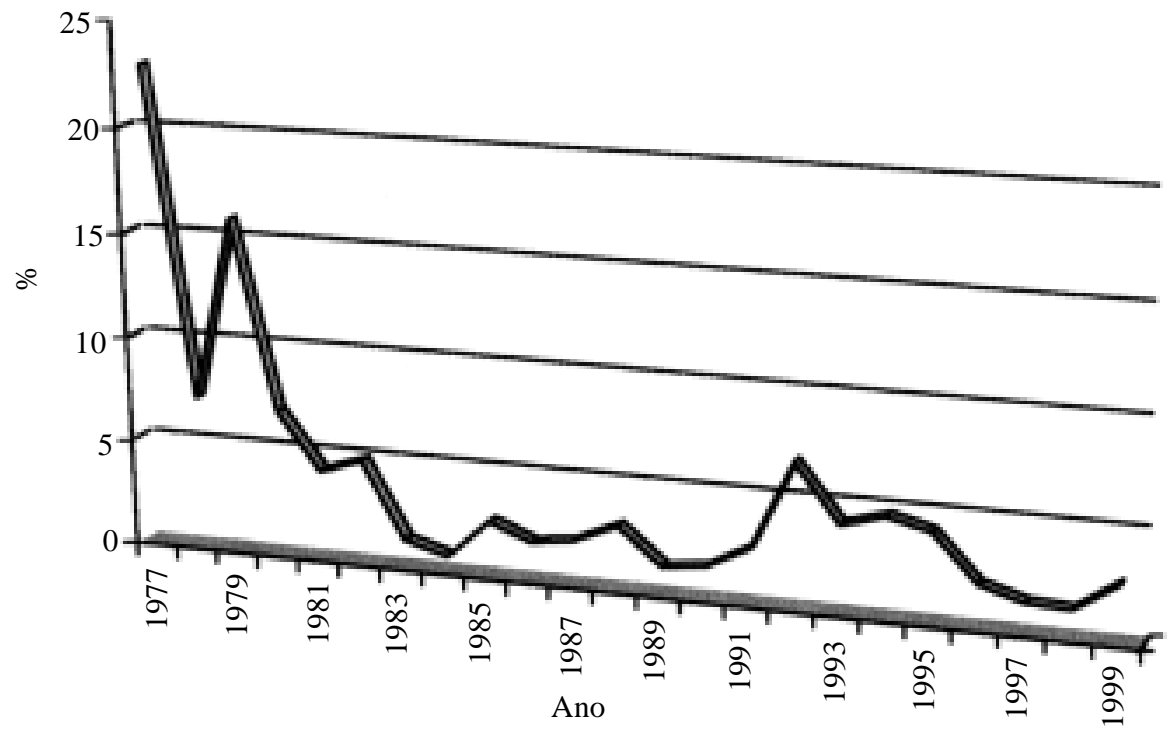

Gráfico 3 - Distribuição da curva de Infecção Respiratória no período de 1977-1999.

A infecção pós-operatória é determinada pela combinação de três fatores ${ }^{2,15}$ :

1. quantidade e tipo de contaminação;

2. técnica cirúrgica e anestésica empregada, e;

3. resistência do hospedeiro.

A criação e o funcionamento da CCIH representaram um progresso na organização da estrutura hospitalar para o estudo e equacionamento de seus múltiplos problemas. A necessidade de reduzir e controlar as taxas de infecção determinou a aplicação de medidas preventivas, educacionais e de controle epidemiológico que visam, através de um processo de conscientização coletiva, levar as taxas de infecção para limites aceitáveis para o tipo de clientela e de procedimentos realizados ${ }^{2}$.
A CCIH do HC da UFPE baseou sua atuação na prevenção e controle da infecção hospitalar nos seguintes campos de atuação:

1. diagnóstico preciso dos casos de infecção;

2. higiene corporal;

3. controle das afecções associadas;

4. internamento pré-operatório mínimo;

5. cuidados com tricotomia;

6. anti-sepsia e assepsia rigorosa;

7. técnica cirúrgica adequada e delicada;

8. divulgação dos resultados da CCIH e da relação infecção/cirurgião/anestesista;

9. rigoroso controle na prescrição de antimicrobianos. 


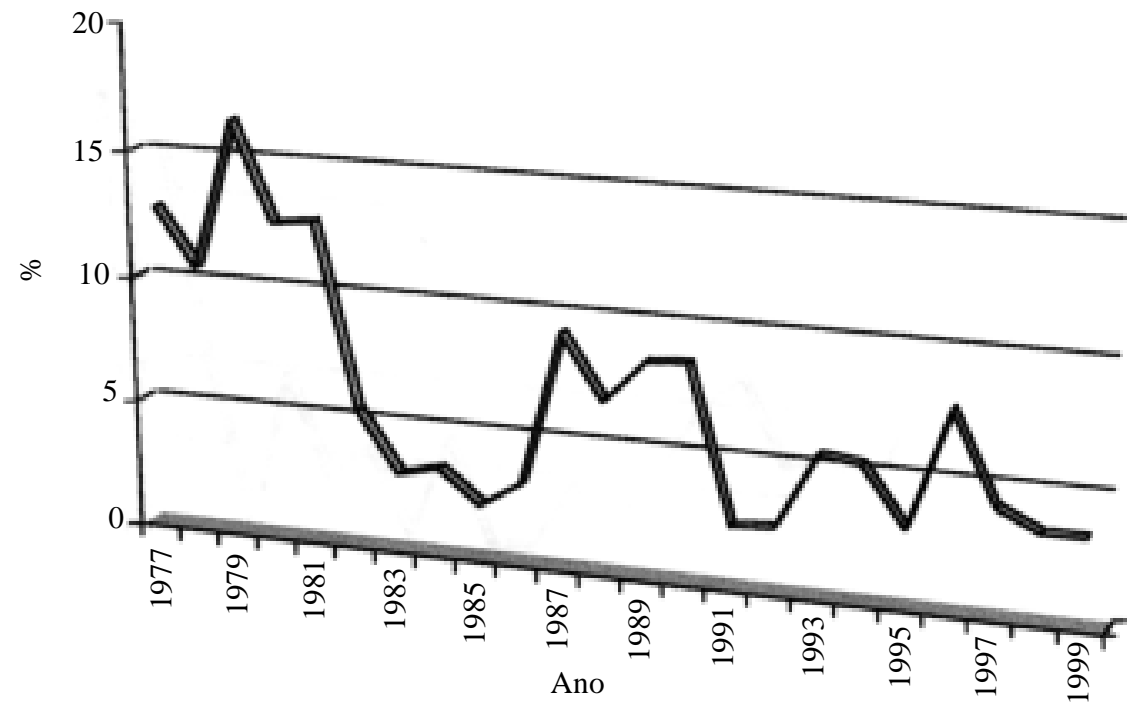

Gráfico 4 - Distribuição da curva de Infecção de Ferida em Cirurgia Limpa no período de 1977-1999.

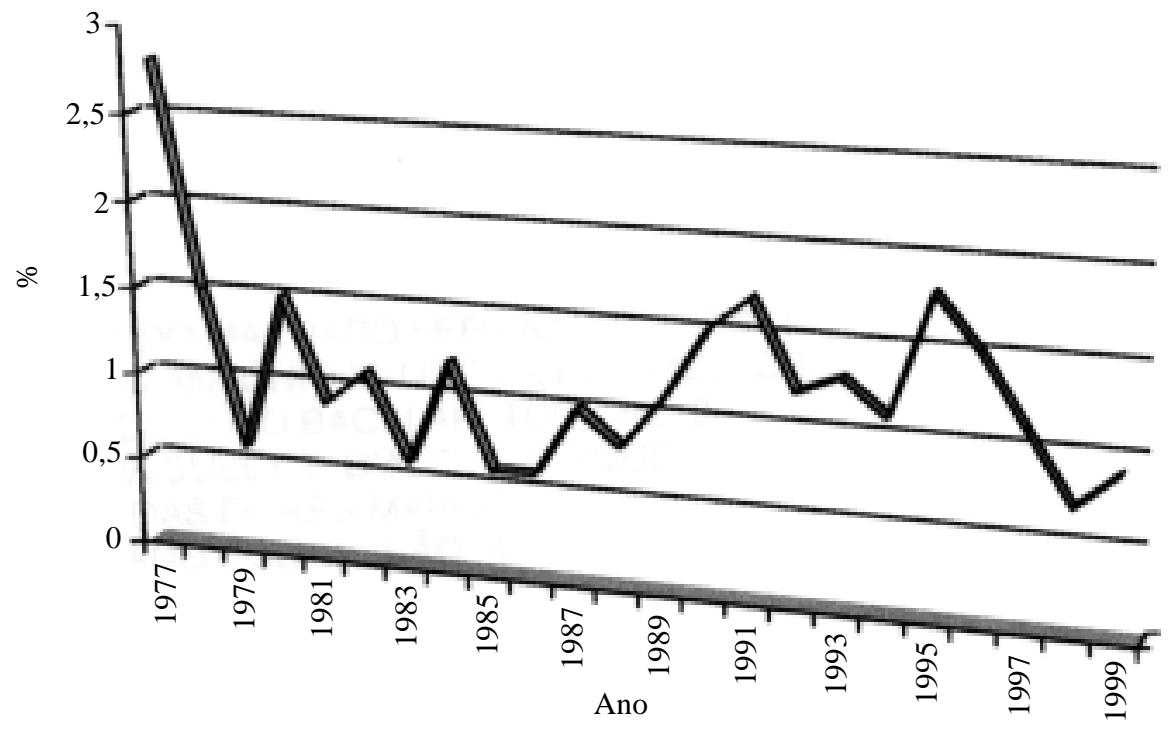

Gráfico 5 - Distribuição da curva de Mortalidade por Infecção no período de 1977-1999.

\section{Diagnóstico preciso}

O ponto fundamental de qualquer programa de controle de infecção hospitalar está na aquisição de dados de maneira correta. É preciso que tenha uma noção exata do problema para poder combatê-lo. A metodologia utilizada consta de: preenchimento obrigatório da ficha de notificação, sistema de busca ativa dos casos de infecção, ambulatório de egressos controlado pela CCIH e identificação dos fatores de risco da instituição. Em trabalho realizado no próprio serviço do HC da UFPE notamos que $42 \%$ das infecções de ferida irão se manifestar entre o sétimo dia até o
14을 dia de pós-operatório. Retardando a retirada de pontos para o 15o dia identificamos $87,6 \%$ dos casos de infecção ${ }^{2,7}$.

\section{Higiene corporal}

Tem sido dada uma importância grande ao asseio corporal e à higiene dos pacientes que são submetidos a procedimentos cirúrgicos. Os pacientes, ainda no ambulatório, são orientados a tomar banho completo e realizar limpezas de áreas críticas do corpo. Na enfermaria os pacientes são novamente banhados (sabão neutro) com especial atenção na cabeça e no local da incisão cirúrgica cerca de duas horas antes da cirurgia ${ }^{2}, 16$. 
Tabela 2

Incidência de Infecção de ferida em cirurgia limpa no período de 23 anos

\begin{tabular}{l|c|cc}
\hline \multirow{2}{*}{ Ano } & № Cirurgias & \multicolumn{2}{c}{ Infecção Ferida } \\
& & № & $\%$ \\
\hline 1977 & 179 & 23 & 12,8 \\
1978 & 180 & 19 & 10,5 \\
1979 & 231 & 38 & 16,4 \\
1980 & 160 & 20 & 12,5 \\
1981 & 204 & 26 & 12,7 \\
1982 & 166 & 09 & 5,4 \\
1983 & 398 & 12 & 3,0 \\
1984 & 289 & 10 & 3,4 \\
1985 & 516 & 11 & 2,1 \\
1986 & 348 & 11 & 3,1 \\
1987 & 226 & 21 & 9,2 \\
1988 & 297 & 20 & 6,7 \\
1989 & 214 & 18 & 8,4 \\
1990 & 163 & 14 & 8,5 \\
1991 & 242 & 06 & 2,4 \\
1992 & 278 & 07 & 2,5 \\
1993 & 273 & 15 & 5,5 \\
1994 & 188 & 10 & 5,3 \\
1995 & 264 & 08 & 3,0 \\
1996 & 272 & 21 & 7,7 \\
1997 & 335 & 14 & 4,2 \\
1998 & 356 & 12 & 3,4 \\
1999 & 328 & 11 & 3,4 \\
\hline TOTAL & 6.107 & $\mathbf{3 5 6}$ & $\mathbf{5 , 8}$
\end{tabular}

\section{Controle das afecções associadas}

A presença de infecção comunitária aumenta em 2-3 vezes o risco de se contrair infecção hospitalar ${ }^{3,16}$. No HC da UFPE cerca de $15 \%$ dos pacientes apresentam infecção comunitária ${ }^{3}$. Deste modo, procuramos, sempre que possível cancelar as cirurgias eletivas quando da identificação de infecções comunitárias. Abreviamos ainda, com o intuito de não subutilizar o centro cirúrgico, a marcação de cirurgia. Deste modo, o intervalo entre a marcação da cirurgia e o procedimento não ultrapassa uma semana.

\section{Internamento pré-operatório mínimo}

O internamento pré-operatório prolongado aumenta o risco de infecção $0^{3,16}$. O internamento pré-operatório acima de três dias dobrou as taxas de infecção de ferida. Pro- curamos internar o paciente no dia da cirurgia, sempre que possível.

\section{Cuidados com tricotomia}

Coelho et al. ${ }^{17}$ verificaram que a tricotomia pode modificar a microbiota do campo operatório. Há um aumento do índice de infecção de ferida quando a tricotomia é realizada com mais de 24 horas ${ }^{16}$. Realizamos a tricotomia cerca de uma hora antes da cirurgia e apenas no local da incisão, o suficiente para a colocação de curativo oclusivo $^{2}$.

\section{Anti-sepsia e assepsia rigorosa}

A preparação da pele com solução degermante de iodo reduz a flora bacteriana da pele em mais de $96 \%{ }^{17}$. Padronizamos a anti-sepsia do campo operatório apenas com solução degermante de iodo a 1\%. Em estudo prospectivo e randomizado sobre as diferentes soluções anti-sépticas não houve qualquer vantagem no acréscimo da solução de álcool iodado, aumentando, aí, as dermatites de contato ${ }^{18}$. Passamos a fabricar as principais soluções anti-sépticas utilizadas no hospital garantindo qualidade e uma economia em cerca de 22 vezes ${ }^{19}$. Padronizamos ainda, a utilização de germicidas, anti-sépticos e as rotinas de limpeza, desinfecção, anti-sepsia e esterilização. Utilizamos as recomendações do Ministério da Saúde ${ }^{2,3,20}$. O curativo da ferida operatória é mantido por apenas 24 horas, sem comprometer com isto, as taxas de infecção de ferida ${ }^{21}$.

\section{Técnica cirúrgica adequada e delicada}

Segundo o Center for Disease Control (CDC), desde que a maioria das infecções pós-cirúrgicas são adquiridas na sala de operações, boa técnica é crucial para a sua prevenção e a maioria das medidas deve ser dirigida para influenciar adequadamente as equipes cirúrgicas ${ }^{22}$. Conte $e t$ al. ${ }^{23}$ consideram que cirurgias com duração acima de três horas aumentam o risco de infecção de 3-4 vezes; que o uso excessivo do bisturi elétrico e a utilização de drenos laminares aumentam em duas vezes a infecção. Além disso, manusear os tecidos delicadamente, evitar sangramentos e a formação de hematomas, erradicar espaço morto, tecido desvitalizado e corpo estranho são essenciais na prevenção da infecção de ferida²,16,22.

Tabela 3

Infecção pós-cirúrgica em cirurgias ambulatoriais de acordo com o risco de contaminação no período de 1983-1999

\begin{tabular}{l|c|cc|c}
\hline Tipo Cirurgia & No & Infecção Ferida & \multicolumn{2}{c}{ Mortalidade } \\
& Cirurgias & No & $\%$ & No \\
\hline Limpa & 18.951 & 95 & 0,5 & 2 \\
Outras & 8.629 & 35 & 0,4 & 0,010 \\
\hline Total & $\mathbf{2 7 . 5 8 0}$ & $\mathbf{1 3 0}$ & $\mathbf{0 , 4}$ & $\mathbf{2}$ \\
\hline
\end{tabular}




\section{Divulgação dos resultados da CCIH e da relação infecção/cirurgião/ anestesista}

Para o tratamento correto de qualquer problema se faz necessário o conhecimento do mesmo. Informações precisas da infecção em um determinado hospital é o ponto de partida para qualquer medida profilática e terapêutica. $\mathrm{O}$ trabalho de qualquer Comissão de Controle de Infecção se baseia essencialmente em um sistema de vigilância epidemiológica e educação da comunidade hospitalar. A divulgação dos resultados faz com que a comunidade hospitalar tenha um retorno de suas ações no intuito de combater a infecção hospitalar. Divulgação de taxas de infecção segmentadas, nos diferentes setores do hospital determina um aumento do compromisso de cada funcionário em sua redução ${ }^{2}$. A divulgação das taxas de infecção de ferida em cirurgia limpa relacionada com o cirurgião, assim como das taxas de infecção respiratória relacionadas ao anestesista é recomendada na maioria dos hospitais americanos ${ }^{3,14,24-26}$ e recomendada e realizada pela CCIH do HC da UFPE. Esta medida é um importante instrumento de educação das equipes cirúrgicas $^{3,14}$. Desde que a técnica cirúrgica é ponto fundamental na gênese da maioria das infecções de ferida em cirurgias limpas, grande ênfase deve ser dada na educação das equipes cirúrgicas.

\section{Rigoroso controle na prescrição de antimicrobianos}

O padrão de resistência bacteriana encontrado em alguns hospitais do mundo tem assustado especialistas no assunto ${ }^{5,6,11,27,28}$. Entre as causas apontadas como responsáveis por este fenômeno, encontram-se o uso indiscriminado de antibióticos dentro e fora de hospitais, automedicação, uso abusivo na agricultura e veterinária ${ }^{3,5,29}$. A padronização da utilização profilática de antibióticos utilizando drogas de primeira linha (cefazolina), em dose única ou enquanto dure a cirurgia e em cirurgias contaminadas está claramente estabelecida em nosso hospital. Nas cirurgias contaminadas utilizamos a antibioticoterapaia apenas durante o procedimento, obedecendo à meia-vida da droga utilizada. Dependendo da microbiota esperada, associamos metronidazol, e em algumas situações mudamos o esquema de profilaxia (cirurgia de cólon). Algumas exceções nas cirurgias limpas estão bem determinadas e têm indicação de antibiótico ${ }^{6,11}$. A utilização de antibióticos mais potentes e de espectro alargado tem prescrição restringida e passa por uma auditoria na CCIH. O sucesso desta prática restritiva está comprovada pelo perfil bacteriológico das nossas bactérias. Não apresentamos, até o momento, problemas de resistência bacteriana importante e a principal bactéria recuperada nas feridas infectadas continua sendo o Staphylococcus aureus ${ }^{3}$.

Nos anos iniciais da experiência de controle de infecção em cirurgia, as taxas de infecção foram bastante ele- vadas. Estes anos iniciais foram de apuro da metodologia na busca dos casos de infecção. Os casos de infecção de ferida se elevaram ainda mais no ano de 1979, quando modificamos a metodologia e criamos o Ambulatório de Egressos, representando um maior apuro no reconhecimento dos acasos ocorridos, particularmente nos pacientes que desenvolviam infecção de ferida após a alta hospitalar. A metodologia nos anos de 1987, 1988 e 1989 foi a mesma, no entanto, o fato de em 1987 terem ocorrido cinco meses de greve e em 88 e 89 três meses cada, foi determinante no aumento das taxas de infecção, pois o descompromisso, o descaso, a falta de disciplina e a quebra da rotina no atendimento do paciente geraram uma deterioração global nos serviços prestados pelo hospital. O período de greve foi o único fator que não esteve presente nos outros anos de nossa experiência ${ }^{3,30}$.

O rigor na indicação do cateter urinário e a utilização de técnica correta, padronizada pela CCIH levaram a uma queda significativa nas taxas de infecção urinária, e que se mantém até os dias atuais.

Quanto à infecção respiratória um exame mais acurado no pré-operatório, com maior controle das patologias respiratórias, com visitas pré-anestésicas, contribuíram sobremaneira para uma queda nas taxas. A divulgação dos índices de infecção respiratória pós-operatória relacionada com o anestesista também contribui para a manutenção de taxas reduzidas ${ }^{2}$. Como o diagnóstico preciso da infecção respiratória é difícil e não há um consenso sobre o assunto, determinamos critérios clínicos para a sua determinação ${ }^{2,3}$.

A mortalidade esteve comparável com os dados da literatura, a despeito de todos os cuidados tomados e dos progressos que, inegavelmente, foram conseguidos ${ }^{16,31,32}$. A mortalidade em torno de $1 \%$ é uma taxa no mínimo esperada em um hospital terciário, de referência e de alta complexidade ${ }^{3}$.

As reduzidas taxas de infecção e mortalidade na cirurgia ambulatorial refletem um tipo de clientela diferenciada. Este tipo de paciente, geralmente é de nível socioeconômico melhor, portador de afecções mais simples, submetido a procedimentos eletivos e que não se colonizam com a flora bacteriana selecionada do hospital. Animados com esses resultados, ampliamos o programa de cirurgia ambulatorial e criamos experiências representativas de hernioplastia inguinal sob anestesia local, que já conta com mais de 600 pacientes operados, sem mortalidade e que inclui pacientes de alto risco (cardiopatas, enfizematosos etc.). Criamos, também, um programa de colecistectomia ambulatorial com anestesia geral, também sem mortalidade ${ }^{33}$. Além destas claras vantagens, isto contribui para reduzir as filas de espera, para tratamento cirúrgico e diminuir o custo do tratamento de inúmeros pacientes.

As taxas de infecção de ferida em cirurgia limpa têm sido utilizadas e preconizadas na determinação de um controle de qualidade dos programas de infecção hospita$\operatorname{lar}^{2,3,8,15,16,22,26}$. Taxas de infecção de ferida em cirurgia lim- 
pa abaixo de 5\% serão sempre perseguidas, mesmo levando-se em consideração o tipo de clientela de cada instituição hospitalar.

A instalação e o pleno funcionamento de uma Comissão de Controle de Infecção Hospitalar são fundamentais na estrutura de uma instituição hospitalar. O que tenta- mos comprovar com a divulgação de nossos resultados é que não são necessários gastos excessivos, equipamentos de última geração ou instalações computadorizadas em ambientes sofisticados. Controle de infecção se faz, ao nosso ver, com decisão política, força de vontade e motivação em controlar o problema.

\begin{abstract}
Background: The aim of this study was evaluate a methodology during 23 years in a public hospital used infection for control of surgeries. Methods: A total of 42,274 surgeries in the General Surgery Division of the Clinics Hospital of the Pernambuco Federal University (January of 1977 until December 1999) were evaluated. The data were acquired through a active search system by the infection control nurse and an epidemiological search during the postoperative period, in the outpatient clinic that centralized all surgical patients after discharge. The infection control committee concentrated its action in the prevention emphasizing precise diagnosis of infections cases; corporal cleaning, control of associated infection, minimal preoperative period, care with the shaving; rigorous asepsia and antisepsia; adequate surgical technique; notification of the infection control results and the infection/surgeon/anesthetist rates; and a rigorous antimicrobial control. Results: Wound infection rate dropped from 15-20\% to the actual rate of $7.7 \%$. Urinary infection was reduced from $18.2 \%$ to $0.4 \%$, and the respiratory infection from $22.9 \%$ to $2.7 \%$. The mortality related to infection was reduced from $2.8 \%$ to $0.9 \%$ and the rate of wound infection in clean surgeries from $12.8 \%$ to $3.4 \%$. In the outpatient surgeries $(27,580)$ the wound infection was $0.4 \%$ and the global mortality was $0.007 \%$. Conclusion: The authors demonstrated that infection control is not made by expensive investments and equipaments, or computadorized ambient. Infection control is made, in our view, by political decision, manpower and motivation to control the infection control problem.
\end{abstract}

Key Words: Infection control; Nosocomial infection; Wound infection; Respiratory infection; Urinary infection; Surgical infection.

\section{REFERÊNCIAS}

1. Ferraz EM, Vasconcelos MDMM, Viana VP et al. Infecção de ferida cirúrgica: avaliação do custo e da permanência hospitalar. Rev. Col. Bras. Cir., 1989, 16(6):253-55.

2. Ferraz EM. Controle de infecção hospitalar. Resultados de um estudo prospectivo de dez anos em um hospital universitário do Recife. 1987. [Tese para Prof. Titular da Disciplina de Técnica Cirúrgica e de Anestesia].

3. Ferraz EM. Infecção da ferida na Cirurgia do Apararelho Digestivo. Tese apresentada para provimento da vaga de Prof. Titular da Cirurgia Abdominal do CCS da UFPE, 1990.

4. Ferraz EM, Ferraz AAB, Bacelar TS. A infecção cirúrgica no contexto das infecções hospitalares. In. Ferraz EM. Infecção em Cirurgia. MEDSI, Rio de Janeiro, 1997. pp. $7-24$.

5. File Jr. TM. Overview of resistence in the 1990s. Chest, 1999; $115: 3 \mathrm{~S}-8 \mathrm{~S}$.

6. Ferraz EM, Ferraz AAB. Antibioticoprofilaxia. In. Ferraz EM. Infecção em Cirurgia. MEDSI, Rio de Janeiro, 1997. pp. 345-352.

7. Ferraz EM, Ferraz AAB, Coelho HSTA et al. Postdischarge surveillance for nosocomial wound infection: does judicious monitoring find cases? Am J Infect Control, 1995; 23(2):290-294.

8. Altemeier WA, Burke JF, Pruitt BA et al. Manual on control of infection in surgical patients of the American College of Surgeons. Philadelphia. J.P. Lippicott, 1976.

9. Ferraz EM. Incidência e custo das infecções; classificação das feridas segundo a etiologia e o risco de infecção. In: Ferraz EM, ed. Manual de controle de infecção em cirurgia do Colégio Brasileiro de Cirurgiões, São Paulo, Editora Pedagógica Universitária, 1982. pp. 9-15.

10. Ferraz EM. Manual de Controle de Infecção em Cirurgia do Colégio Brasileiro de Cirurgiões, São Paulo, Editora Pedagógica Universitária Ltda, 1982.

11. Ferraz EM, Ferraz AAB, Menezes PPB et al. Uso de antibióticos em cirurgia geral: avaliação prospectiva de 4.036 intervenções em um período de 10 anos. Rev Bras Cir 1994, 84:253.

12. Ferraz EM, Bacelar TS, Ferreira Filho HA, et al. Estudo prospectivo e randomizado do uso profilático da Ceftriaxona ou Cefalotina em Cirurgia Geral. Folha Médica, 1988, 8(1/2):53-57.

13. Silveira M, Vanderlei MI, Kelner S. Avaliação nutricional e imunológica em pacientes adultos candidatos a cirurgia do aparelho digestivo. Rev Col Bras Cir, 1987; 14:133141.

14. Condon RE, Haley RW, Lee JT et al. Does infection control control infection? Arch Surg, 1988; 123:250-256.

15. Ferraz EM, Bacelar TS, Aguiar JLA et al. Wound Infection Rates in Clean Surgery: a potentially Misleading Risk Classification. Inf Control Hosp Epi, 1992, 13(8): 457-462. 
16. Cruse PSG, Foord M. The epidemiology of wound infection. Surg Clin North Am, 1980; 60:27-40.

17. Coelho JCU, Buffara VA, Wiedekher JC et al. Avaliação da tricotomia pré-operatória na flora bacteriana da pele. Rev Bras Cir, 1988; 78(5):307-309.

18. Ferraz EM, Santos MJT, Menezes PPB et al. Estudo prospectivo randomizado do uso de um antisséptico tópico no campo operatório. An Fac Med CCS, 1992; 37(1):5154.

19. Ferraz EM, Santos MJT Ferraz AAB et al. Avaliação do custo de antissepticos tópicos para uso hospitalar. Ver. IMIP 1989; 3(1):24-26.

20. Vasconcelos MDM, Góes EA, Oliveira RB et al. Avaliação da limpeza da sala cirúrgica com detergente. Revista do IMIP, 5(1):34-37, 1991.

21. Pagnossin G, Ferraz AAB, Wanderley GJP et al. Curativo no pós-operatório de cirurgia geral. Rev Col Bras Cir, 1992; 19(3):116-119.

22. Garner JS. CDC Guideline for prevention of surgical wound infections, 1985. Infection Control, 1986, 7(3): 193-200.

23. Conte Jr JE, Jacob L, Polk Jr HC. Antibiotic prophylaxis in Surgery. A comprehensive review. J.B. Lippincott Company, Philadelphia, 1984.

24. Altemeier WA, Burke JF, Pruitt BA, Sandusky WR. Manual on control of infection in surgical patients of the American College of Surgeons. Philadelphia J P Lippincott, 1976.

25. Mead PB, Pories SE, Hall P. Decreasing the incidence of surgical wound infections: validation of a surveillance notification program. Arch Surg, 1986; 121:458-461.

26. Olson M, O'Connor M, Schwartz ML. Surgical wound infection. A 5 year prospective study of 20,193 wounds at the Minneapolis V.A. Medical Center. Ann Surg, 1984; 199(3):253-259.

27. Barg N. New resistence mechanisms of common bacterial pathogens. Contemp Intern Med, 1995, 7:61-69.
28. Eliopoulos GM. Vancomycin-resistent enterococci: mechanism and clinical relevance. Infect. Dis Clin North Am, 1997; 11:851-865.

29. Ferraz EM. Changing antibiotic usage in Brazil. 1989, APUA Newsletter, 1989; 7(1):1-2.

30. Ferraz EM, Porfírio L, Bacelar TS et al. Controle de infecção em cirurgia geral: resultados de um estudo prospectivo de 13 anos e de 17.503 operações. Rev Col Bras Cir, 1992; 19(4):169-174.

31. Ferraz EM, Correa Lima JF, Porfírio L et al. Mortalidade pós-operatória em cirurgia geral. Rev Col Bras Cir, 1982; 9:222-4.

32. Meakins JL. Surgical infections in critical care medicine. Churchill Livignstone, New York, 1985.

33. Ferraz EM, Bacelar TS, Melo E et al. Cholecystectomy by minilaparotomy on an outpatient basis: an analysis of 36 patients. Arq Bras Cir Dig 1992; 7(3):47-50.

Endereço para correspondência:

Edmundo Machado Ferraz

Rua Dom Sebastião Leme 171/2501

52011-160 - Recife-PE

E.mail - edferraz@truenet.com.br 